\title{
Pulp volume changes after piezocision-assisted tooth movement: a randomized clinical trial
}

\author{
Abdulkarim A. Hatrom ${ }^{1}$, Mohammed S. Howait ${ }^{2}$, Khalid H. Zawawi ${ }^{3}$, Ghassan A. Al-Turki ${ }^{3}$, Reem A. Alansari ${ }^{3}$, \\ Nouf F. Almehayawi ${ }^{4}$, Sarah H. Alammari ${ }^{4}$, Raghda A. Mohammed ${ }^{5}$ and Ali H. Hassan ${ }^{3,6^{*}}$
}

\begin{abstract}
Background: Orthodontic treatment may result in undesirable side effects, such as root resorption and a decrease in the size of the pulp tissue which could be associated with the duration of the orthodontic treatment. Piezocisionassisted tooth movement was introduced as a minimally invasive surgical procedure to shorten orthodontic treatment time. This prospective randomized clinical trial was aimed to compare the pulp volume changes of maxillary anterior teeth after en-masse retraction with or without piezocision-assisted orthodontics.
\end{abstract}

Methods: Patients who required orthodontic treatment with bilateral maxillary first premolar extractions and enmasse retraction were recruited. Patients were randomly divided into extraction with piezocision, or only extraction, serving as controls. Pulp volume and root length changes of the maxillary six anterior teeth were measured and compared between the two groups using a 3-Dimensional analytical software. Paired and independent sample t-tests were used to compare within and between groups. Bivariate correlation was done between the mean change in pulp volume and its corresponding root length. The significance level was set at $a=0.05$.

Results: A total of 23 patients were included, 12 in the piezocision, and 11 in the control group. At the end of the enmasse retraction phase, (mean $=122.74 \pm 3.06$ days) pulp volume was significantly decreased in all six anterior teeth in both groups $(P<0.01)$. The decrease in pulp volume was not statistically different between both groups, $(P>0.05)$. There was a statistically significant but moderate correlation only between the pulp volume change of the right canine and its root length, $r=0.44, P=0.034$.

Conclusions: The effect of piezocision-assisted orthodontic tooth movement on the pulp volume was comparable to the conventional orthodontic treatment. The degree of change in pulp volume does not appear to be related to the amount of root resorption.

Trial registration NCT03180151. Registered December 25, 2016, retrospectively registered, https://clinicaltrials.gov/ct2/ show/record/NCT03180151.

Keywords: Cone-beam computed tomography, Dental pulp, Dental pulp cavity, Orthodontic, Piezocision, Tooth movement

\section{Background}

\footnotetext{
${ }^{*}$ Correspondence: aakbr@kau.edu.sa

${ }^{3}$ Department of Orthodontics, Faculty of Dentistry, King Abdulaziz University, Jeddah, Saudi Arabia

Full list of author information is available at the end of the article
}

During orthodontic tooth movement, tissues that are affected by orthodontic force application include the periodontal tissues, root length, and the pulp tissues [1-4]. The effect of orthodontic forces on pulp tissues has been the subject of interest with inconsistent 
results. Several studies have demonstrated a negative impact from orthodontic force application on the pulp tissues [3, 5-9]. While others did not find a relationship [10-12].

In an animal study, changes that occurred in the dental pulp as a result of orthodontic forces were observed in the form of pulpal aging and disruption of the odontoblastic layer at various locations [13]. Human pulpal response to orthodontic forces after 5 and 10 days showed a significant increase in angiogenesis and the degree of the pulpal response and was found to be dependent on the force applied [6]. These changes ranged from a minor alteration in the pulp vasculature to a decrease in respiration rate of the tissue, vacuolization of odontoblasts, apoptosis, alteration of alkaline phosphatase level and tissue damage aspiration [14]. When assessing the pulp size before and after orthodontic treatment with maxillary premolar extraction using cone-beam computed tomography (CBCT) found that the size of the pulp was significantly decreased following orthodontic treatment [8]. A recent study investigated the effect of forces applied by the rapid palatal expansion appliance on pulp volume [9]. They found a decrease in pulp volume at the end of the expansion.

The detection of pulp changes is commonly performed using periapical and cephalometric radiographs. However, these methods have inherited drawbacks such as magnification errors and reduced accuracy $[15,16]$. Moreover, measuring the pulp cavity area using conventional 2-dimensional radiographs is not reliable. Histologic studies conducted to assess pulp changes due to orthodontic forces and tooth movement are accurate [14]. Unfortunately, this method can only be performed on extracted teeth, rendering it clinically inapplicable. Cone-beam computed tomographic (CBCT) imaging has modernized orthodontic diagnosis and treatment planning as well as being an accurate tool to detect root resorption with high sensitivity and specificity and enables accurate measurement of pulp volume $[8,9,16,17]$.

Piezocision-assisted orthodontic tooth movement was introduced as a more conservative surgical procedure to shorten orthodontic treatment time [18]. Thus far, the effect of piezocision-assisted en-masse tooth movement on pulp volume has never been investigated. Therefore, this study aimed to evaluate the changes in pulp volume after piezocision-assisted orthodontic tooth movement at the end of the en-masse retraction phase. A secondary aim was to evaluate the association between the change in pulp volume and root resorption.

\section{Methods}

This parallel randomized clinical trial was approved by the Research Ethics Committee of the Faculty of Dentistry at King Abdulaziz University (No. 078-16) and the ethical standards of the Declaration of Helsinki. The research was registered under the Clinical Trial Registry (NCT03180151) and the updated CONSORT statement for reporting randomized clinical trials was followed.

The study sample was taken from a previous clinical trial [19]. Briefly, Orthodontic patients were recruited from the Faculty of Dentistry at King Abdulaziz University according to the following inclusion criteria: (1) patients age between 16-26 years, (2) half cusp or more Class II division 1 malocclusion, (3) mild or no crowding, (4) maxillary arches requiring bilateral first premolar extractions as part of the orthodontic treatment plan, and (5) good oral hygiene and healthy periodontal condition. The exclusion criteria were: (1) history of systemic disease, (2) presence of dental or facial anomalies, (3) patients receiving treatment that may affect bone biology and/or tooth movement, and (4) history of periodontal surgery. After obtaining informed consent, a simple randomization method was used as follows: patients were randomly assigned into two equal groups: (1) piezocision group $(n=13)$ and (2) control group $(n=13)$, using the opaque sealed envelope technique.

Sample size calculation was based on the post hoc power analyses using $G$ Power[20] with effect size $d=2.03$, power $(1-\beta)$ set at 0.95 and $a=0.05$, twotailed. The analysis showed that power reaches 0.916 when sample sizes are Piezocision group $=12$ and Control group $=11$ for group differences to reach statistical significance at the 0.05 level. This analysis showed that our sample size did not compromise the statistical power and was sufficient on effect size observed on the basis of the mean between-group comparison.

All patients were treated using a modified bidimensional bracket system 0.018 -inch slots in the six anterior teeth and 0.022-inch slots in the posterior teeth (Gemini Series Bracket; 3 M Unitek, Monrovia, CA, USA). Also, all patients had miniscrews (3 M Unitek, Monrovia, Calif, USA) inserted bilaterally between the maxillary first molar and second premolar. After leveling and alignment, all patients had their upper first premolars extracted. In the piezocision group, a canine to canine piezocision decortication was performed only labially during the extraction procedure and no grafting was done. The enmasse retraction was started a week later for both groups on a $0.018 \times 0.025$-inch stainless steel arch-wire through nickel-titanium active coil springs delivering a bilateral 250grams of force. To monitor the force level, a strain caliper was used (Dentaurum, Ispringen, Germany). 
During the study, one patient from the piezocision group and two patients from the control group were excluded due to miniscrew failure. Hence, 23 participants completed the study, 12 in the piezocision group, and 11 in the control group.

$\mathrm{CBCT}$ images were acquired using the i-CAT next generation CBCT machine (I-CAT Cone Beam 3D Imaging, Imaging Sciences International Hatfield, PA, USA). $\mathrm{CBCT}$ images were taken during the initial orthodontic records visit (T0) and at the end of en-masse retraction, mean $=122.74 \pm 3.06$ days (T1). Pulp volume of each of maxillary anterior teeth (canine to canine) was measured by one blinded investigator using an image processing software (Mimics Version 14 on Windows; Materialize, Leuven, Belgium). Pulp volume measurements were performed by segmenting and separating the images of the selected teeth (maxillary central and lateral incisors and canines) which were carried out by grayscale threshold as previously described [8]. Briefly, using the axial, sagittal, and coronal views, a mask was built and cropped in these 3 axes to segment the pulp cavity of the selected tooth, then an optimum separating grayscale threshold was selected. The threshold values were established separately with the same Hounsfield Units (HU) for each tooth at $\mathrm{T} 0$ and $\mathrm{T} 1$, then the calculation of the 3-dimensional image was performed. The mask of the pulp cavity in 3-dimensional allowed the operator to calculate the pulp volume (Fig. 1). The root lengths of each maxillary six anterior teeth were measured along the long axis of the teeth using the CBCT frontal view. The measurements were recorded from the middle of the cementoenamel junction to the root apex.

Intra-examiner reliability was tested using the intraclass correlation coefficient (ICC). Measurements of 10 participants were repeated after 2 weeks to assess measurement errors. The ICC coefficient ranged between 0.79 and $0.98 \%$, indicating excellent reliability.

\section{Statistical analysis}

Descriptive statistics (means and standard deviations) were calculated. The normality of the main dependent variables tested using the Shapiro-Wilks test $(P>0.05)$ showed that they were almost normally distributed in both groups. Paired t-tests were used to compare mean changes ( $\mathrm{T} 0$ vs $\mathrm{T} 1$ ) within groups and independent sample $t$-tests were used to compare mean differences (T0 - T1) between groups. Chi-square was used to test the distribution of males and females between and within groups. Pearson's correlation coefficient was used to assess the relationship between the mean changes of each tooth pulp volume and its root length. Data were analyzed using the Statistical Package for Social

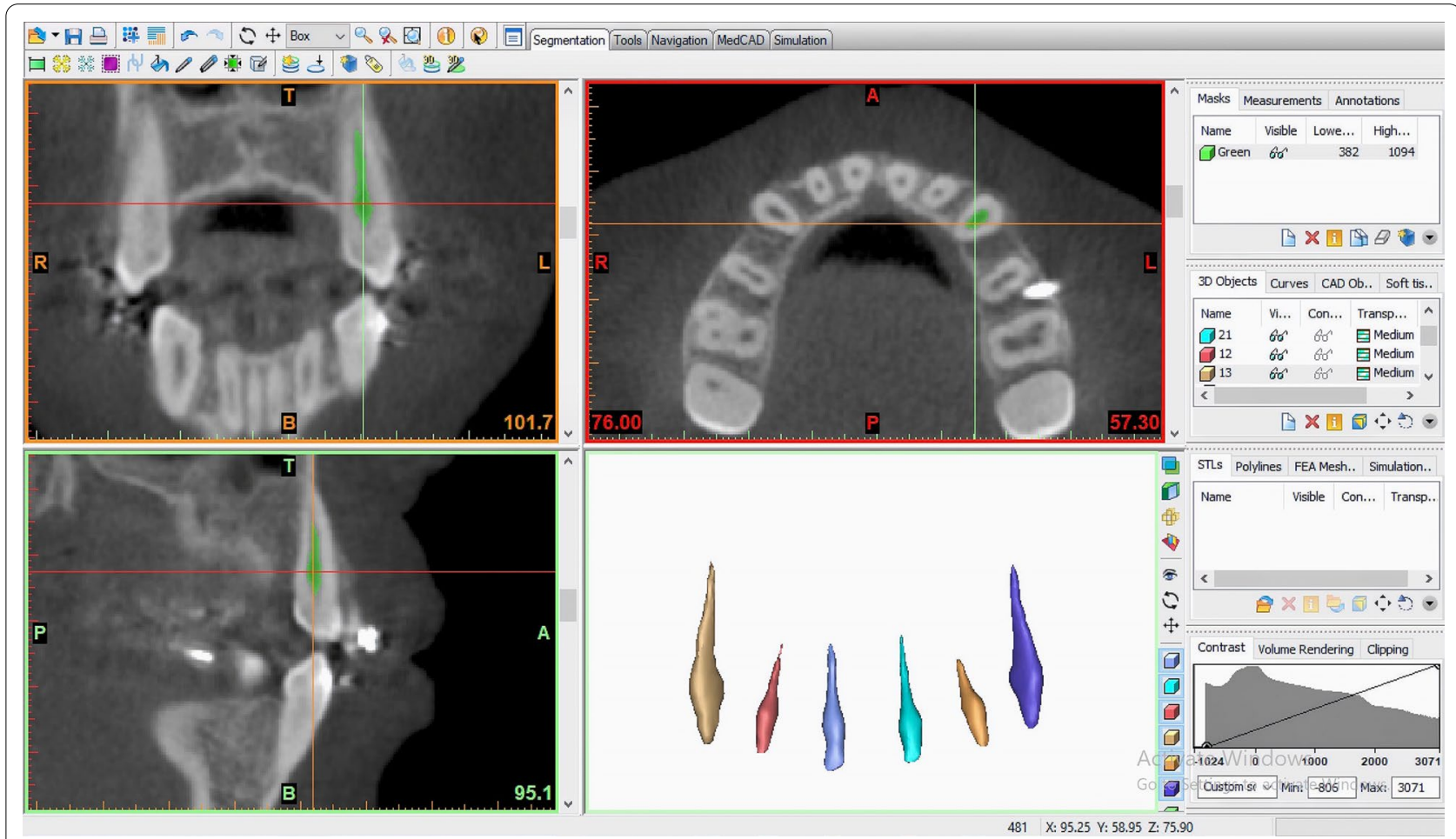

Fig. 1 Screenshot image for one of the included patients illustrating the segmented pulp tissue, from the CBCT scan, in all 3 planes of space and source of 3-Dimensional images of the pulp cavities for the maxillary anterior teeth (image rendered using Mimics imaging software) 
Sciences (IBM SPSS Statistics for Macintosh, Version 26.0. Armonk, NY, USA). The significance level was set at $\alpha=0.05$ by a statistician who was blinded to the results.

\section{Results}

A total of 26 participants were included in this study (Fig. 2), 13 in the piezocision group (7 males, 6 females) and 13 in the control group ( 6 males, 7 females). The enrollment began in September 2016 and completed in January 2018. from the 26 patients enrolled, one patient in the piezocision group, and two patients in the control group were eliminated after enrollment due to miniscrews failure. At the commencement of the trial the mean age of the patients allocated to the piezocision group was $19.27( \pm 3.38)$ years while the mean age of the control group was $20.83( \pm 3.64)$ years.

Descriptive statistics and comparisons between both groups are presented in Table 1 . There was no statistically significant difference in age between the groups $(P=0.30)$. The chi-square test showed that there was equal gender distribution in both groups $(P=0.99)$. Also, all initial measurements (T0) were not significantly different between both groups.

Table 2 shows the comparison of pulp volume means within and between the piezocision and control groups. There was a statistically significant decrease in pulp volume at the end of en-masse retraction in both groups for all anterior teeth $(P<0.01)$. When comparing the mean change in pulp volume in the piezocision and control groups, no significant differences were observed, $P>0.05$ (Table 2).

As shown in Table 3, there was a statistically significant root resorption at the end of en-masse retraction in both the piezocision and control group. Only the right and left central incisors and right canine showed statistically significantly more root resorption in the control group compared to the piezocision group $(0.09 \pm 0.39,1.00 \pm 0.53$, and $1.03 \pm 0.63$, respectively), $P<0.05$.

Pearson's correlation coefficient was calculated between the mean changes of each tooth pulp volume and its root length (Table 4). There was only a statistically significant but moderate correlation in the maxillary right canine, $\mathrm{r}=0.44, P=0.034$. No significant

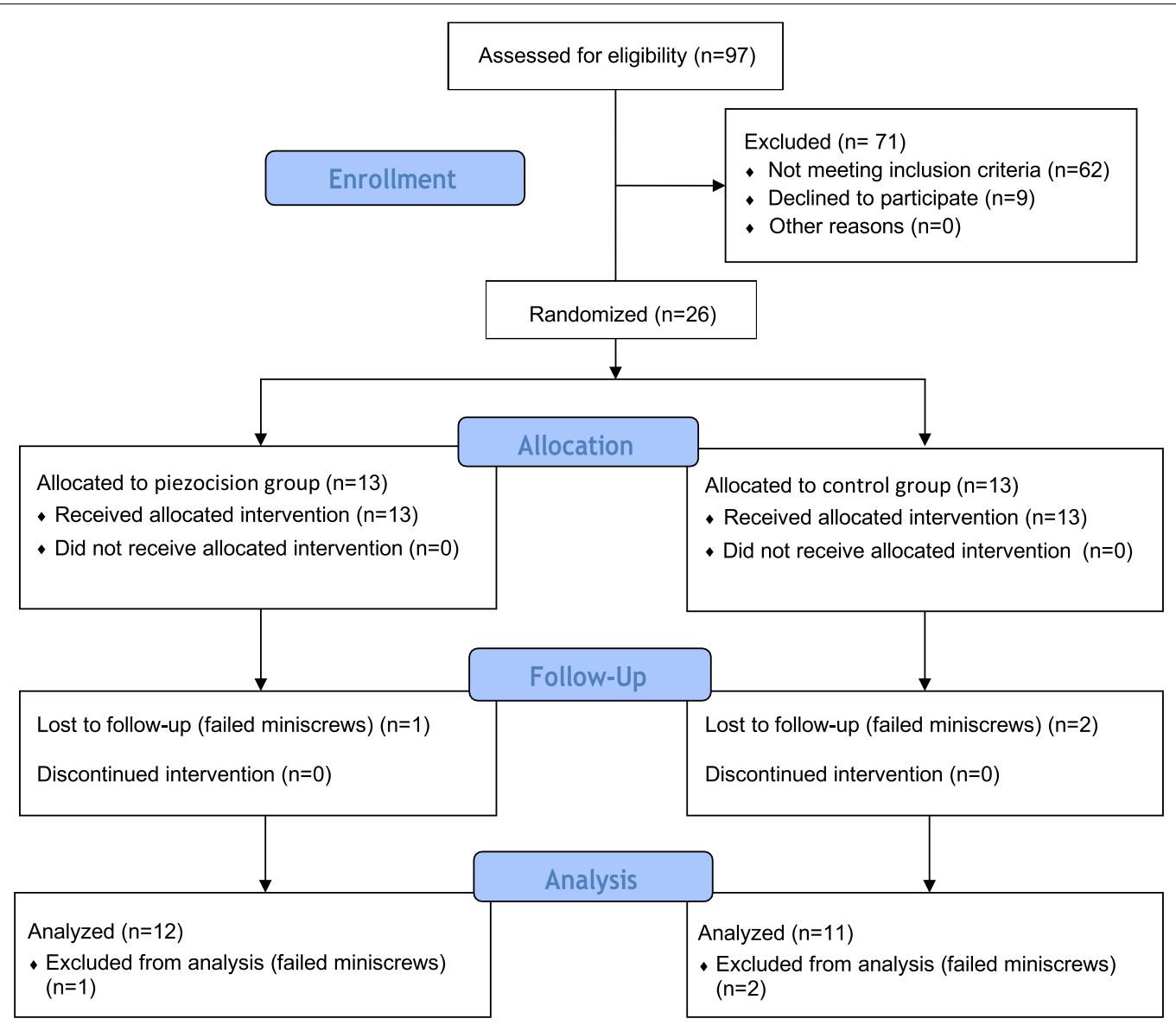

Fig. 2 CONSORT flow diagram 
Table 1 Descriptive summary of initial measurements (TO) and intergroup comparisons of pulp volume and gender distribution

\begin{tabular}{llll}
\hline Variables & Piezocision group $(\mathbf{n = 1 2 )}$ & Control group $(\mathbf{n}=\mathbf{1 1})$ & $\boldsymbol{p}$ value \\
\hline Age (years) & $19.27 \pm 3.38$ & $20.83 \pm 3.64$ & 0.30 \\
Gender $[\mathrm{n}(\%)]$ & Male $=6(55 \%)$ & Male $=5(45 \%)$ & $0.99^{*}$ \\
& Female $=6(50 \%)$ & Female=6(50\%) & \\
Pulp Volume $\left(\mathrm{mm}^{3}\right)$ & & & \\
Right central & $31.71 \pm 9.67$ & $33.15 \pm 12.95$ & 0.76 \\
Right lateral & $23.72 \pm 6.03$ & $23.24 \pm 10.86$ & 0.90 \\
Right canine & $46.84 \pm 16.42$ & $45.26 \pm 14.53$ & 0.81 \\
Left central & $31.22 \pm 9.65$ & $32.56 \pm 10.90$ & 0.76 \\
Left lateral & $22.28 \pm 7.17$ & $23.73 \pm 11.63$ & 0.72 \\
Left canine & $46.11 \pm 14.04$ & $48.40 \pm 15.34$ & 0.71 \\
\hline
\end{tabular}

Data are presented as mean $\pm \mathrm{SD}$, Gender is presented as number $(\%),{ }^{*}$ Chi square test

Table 2 Comparisons of pulp volume means within and between the Piezocision and Control groups

\begin{tabular}{|c|c|c|c|c|c|c|c|c|c|}
\hline \multirow{2}{*}{$\begin{array}{l}\text { Pulp volume } \\
\left(\mathrm{mm}^{3}\right)\end{array}$} & \multicolumn{3}{|c|}{ Piezocision group $(n=12)$} & \multirow{2}{*}{$\begin{array}{l}\text { T0 versus T1 } \\
P \text { value }\end{array}$} & \multicolumn{3}{|c|}{ Control group $(n=11)$} & \multirow{2}{*}{$\begin{array}{l}\text { T0 versus T1 } \\
P \text { value }\end{array}$} & \multirow{2}{*}{$\begin{array}{l}\text { Piezocision } \\
\text { versus control } \\
\text { P value }\end{array}$} \\
\hline & TO & $\mathrm{T} 1$ & Mean diff & & TO & T1 & Mean diff & & \\
\hline ght central & $\begin{array}{l}31.71 \\
\pm 9.67\end{array}$ & $30.79 \pm 9.64$ & $0.92 \pm 0.82$ & 0.003 & $33.15 \pm 12.95$ & $32.19 \pm 12.89$ & $0.97 \pm 0.42$ & 01 & 0.87 \\
\hline Right lateral & $23.72 \pm 6.03$ & $22.34 \pm 6.42$ & $1.38 \pm 0.97$ & $<0.001$ & $23.24 \pm 10.86$ & $22.16 \pm 11.01$ & $1.09 \pm 0.68$ & $<0.001$ & 0.40 \\
\hline Right canine & $46.84 \pm 16.42$ & $45.77 \pm 16.41$ & $1.08 \pm 0.55$ & $<0.001$ & $45.26 \pm 14.53$ & $44.01 \pm 14.48$ & $1.25 \pm 0.84$ & 0.001 & 0.56 \\
\hline Left central & $31.22 \pm 9.65$ & $30.37 \pm 9.58$ & $0.84 \pm 0.51$ & $<0.001$ & $32.56 \pm 10.90$ & $31.30 \pm 10.85$ & $1.25 \pm 0.71$ & $<0.001$ & 0.13 \\
\hline Left lateral & $22.28 \pm 7.17$ & $21.26 \pm 6.99$ & $1.02 \pm 0.78$ & 0.001 & $23.73 \pm 11.63$ & $22.82 \pm 11.43$ & $0.90 \pm 0.43$ & $<0.001$ & 0.67 \\
\hline Left canine & $46.11 \pm 14.04$ & $45.02 \pm 13.88$ & $1.09 \pm 0.74$ & $<0.001$ & $48.40 \pm 15.34$ & $47.47 \pm 15.30$ & $0.93 \pm 0.64$ & 0.001 & 0.59 \\
\hline
\end{tabular}

Data are presented as mean $\pm \mathrm{SD}, \mathrm{T} 0=$ initial, $\mathrm{T} 1=$ end of en masse retraction

Table 3 Comparisons of root length means within and between the Piezocision and Control groups

\begin{tabular}{|c|c|c|c|c|c|c|c|c|c|}
\hline \multirow[t]{2}{*}{ Root length } & \multicolumn{3}{|c|}{ Piezocision group $(n=12)$} & \multirow{2}{*}{$\begin{array}{l}\text { T0 versus T1 } \\
p \text { value }\end{array}$} & \multicolumn{3}{|c|}{ Control group $(n=11)$} & \multirow{2}{*}{$\begin{array}{l}\text { T0 versus T1 } \\
p \text { value }\end{array}$} & \multirow{2}{*}{$\begin{array}{l}\text { Piezocision } \\
\text { versus control } \\
p \text { value }\end{array}$} \\
\hline & TO & T1 & Mean diff & & T0 & $\mathrm{T} 1$ & Mean diff & & \\
\hline Right central & $25.04 \pm 1.04$ & $24.47 \pm 1.17$ & $0.58 \pm 0.27$ & $<0.001$ & $25.06 \pm 1.41$ & $24.16 \pm 1.47$ & $0.90 \pm 0.39$ & $<0.001$ & 0.030 \\
\hline Right lateral & $22.88 \pm 0.75$ & $22.44 \pm 0.81$ & $0.44 \pm 0.30$ & $<0.001$ & $23.38 \pm 1.53$ & $22.56 \pm 1.39$ & $0.82 \pm 0.60$ & 0.001 & \\
\hline Right canine & $27.28 \pm 1.29$ & $26.69 \pm 1.41$ & $0.58 \pm 0.27$ & $<0.001$ & $27.68 \pm 2.16$ & $26.68 \pm 1.97$ & $1.00 \pm 0.53$ & $<0.001$ & 0.025 \\
\hline Left central & $25.23 \pm 0.98$ & $24.63 \pm 0.93$ & $0.60 \pm 0.26$ & $<0.001$ & $25.25 \pm 1.33$ & $24.22 \pm 1.43$ & $1.03 \pm 0.63$ & $<0.001$ & 0.046 \\
\hline Left lateral & $22.91 \pm 0.77$ & $22.28 \pm 0.81$ & $0.63 \pm 0.25$ & $<0.001$ & $23.53 \pm 1.69$ & $22.70 \pm 1.54$ & $0.83 \pm 0.34$ & $<0.001$ & 0.140 \\
\hline Left canine & $27.14 \pm 1.12$ & $26.50 \pm 1.12$ & $0.64 \pm 0.26$ & $<0.001$ & $27.47 \pm 1.79$ & $26.66 \pm 1.64$ & $0.81 \pm 0.30$ & $<0.001$ & 0.163 \\
\hline
\end{tabular}

Data are presented as mean $\pm \mathrm{SD}, \mathrm{T} 0=$ initial, $\mathrm{T} 1=$ end of en masse retraction,

correlations were observed between the pulp volume of the remaining teeth and their root lengths $(P>0.05)$.

\section{Discussion}

The cause and effect relationship between orthodontic tooth movement and dental pulp volume and root resorption is still a challenging phenomenon [1-12, 21, 22]. It is well recognized that orthodontic forces do affect teeth in many aspects including the periodontium, root length, and pulp structure [16, 23, 24]. Dental pulp was found to react to orthodontic forces in different ways, but in general, pulp responds by forming tertiary dentin after its irritation [25]. These types of repair could adversely affect the volume of the pulp. Multiple studies tested the effect of orthodontic tooth movements by using, for example, histological assessment using light or scanning electron 
Table 4 Bivariate correlations between pulp volume and root resorption

\begin{tabular}{|c|c|c|c|c|c|c|}
\hline & \multicolumn{6}{|c|}{ Root resorption } \\
\hline & Central right & Lateral right & Canine right & Central left & Lateral left & Canine left \\
\hline \multicolumn{7}{|l|}{ Pulp volume } \\
\hline \multirow[t]{2}{*}{ Central right } & 0.14 & 0.28 & 0.20 & 0.14 & 0.25 & -0.01 \\
\hline & $(0.51)$ & $(0.20)$ & $(0.35)$ & $(0.51)$ & $(0.25)$ & $(0.96)$ \\
\hline \multirow[t]{2}{*}{ Lateral right } & -0.05 & 0.18 & -0.03 & -0.05 & -0.17 & -0.04 \\
\hline & $(0.82)$ & $(0.42)$ & $(0.91)$ & $(0.82)$ & $(0.45)$ & $(0.85)$ \\
\hline \multirow[t]{2}{*}{ Canine right } & 0.15 & 0.09 & 0.44 & 0.15 & 0.41 & 0.09 \\
\hline & $(0.50)$ & $(0.69)$ & $(0.03)$ & $(0.50)$ & $(0.05)$ & $(0.70)$ \\
\hline \multirow[t]{2}{*}{ Central left } & -0.03 & 0.47 & 0.21 & -0.03 & 0.13 & -0.11 \\
\hline & $(0.90)$ & $(0.03)$ & $(0.34)$ & $(0.90)$ & $(0.57)$ & $(0.62)$ \\
\hline \multirow[t]{2}{*}{ Lateral left } & -0.13 & 0.02 & -0.22 & -0.13 & -0.37 & -0.15 \\
\hline & $(0.55)$ & $(0.91)$ & $(0.31)$ & $(0.55)$ & $(0.08)$ & $(0.51)$ \\
\hline \multirow[t]{2}{*}{ Canine left } & -0.21 & 0.26 & -0.22 & -0.21 & -0.14 & -0.16 \\
\hline & $(0.34)$ & $(0.24)$ & $(0.31)$ & $(0.34)$ & $(0.53)$ & $(0.46)$ \\
\hline
\end{tabular}

Data are presented as correlation coefficient " $r$ " and ( $p$ value)

microscopy and 2-dimensional radiograph [3, 14, 26-28]. These methods, however, have a limitation that could reduce their accuracy. The 3-dimensional measuring technique used in the current study provided an accurate method for the evaluation of the pulp volume during orthodontic treatment. In one study, 3-dimensional radiography was used to assess pulp volume changes concurrent with orthodontic treatment [8]. Pulp volume of the anterior teeth was found to undergo significant reduction after orthodontic treatment. They attributed their findings to the protective reaction of the pulp to the irritation caused by orthodontic teeth movements, which led to the formation of tertiary dentin that restricted the available pulp volume [8]. They concluded that the pulp volume undergoes a significant reduction in the anterior teeth after orthodontic treatment. This reduction of the pulp volume could be explained by the possible alterations in the pulpal blood supply and inflammation caused by orthodontic teeth movement that may have led to a mild irritation to odontoblastic layer surrounding the pulp and the release of inflammatory mediators that stimulates odontoblast and odontoblast-like cells, leading to the deposition of tertiary dentin with the eventual reduction in pulp space $[29,30]$.

In our study, the percentage of pulp volume reduction was $3.4 \%$ in the piezocision group and $2.7 \%$ in the control group. These percentages are not consistent with Venkatesh et al.[8]. This difference could be conjectured by the shorter duration of our study which did not allow sufficient time for secondary dentine to form $[25,30]$. The time limit in our study was selected based on the fact that the effect of the regional acceleratory phenomenon peaks at 1 to 2 months, and weakens after 4 to 6 months [31].
Another explanation for the different results could be due to the mechanics used in our study during tooth movement. The current study also found that the change in pulp volume was not related to root resorption and that both responses could be mutually independent. Since there are no other similar studies, comparison to our findings is difficult to conduct.

A limitation of the current study was the small sample size as the sample was taken from a previous study [19]. Still, the sample size is similar to previous root resorption and pulp volume studies [9,32]. Another limitation is that it cannot be used to predict the long-term effect of piezocision-assisted orthodontic tooth movement on the pulp volume. Furthermore, since this was a radiographical study, the nature of pulp volume reduction cannot be determined. In addition, histological changes in the pulp cannot be assessed by this technique. Future histological studies to evaluate the biological mechanism with larger samples are warranted. Moreover, this study was limited to the maxilla future study are required to evaluate change of pulp volume in both jaws.

\section{Conclusion}

The effect of piezocision-assisted orthodontic tooth movement on the pulp volume was comparable to the conventional orthodontic treatment. The degree of change in pulp volume does not appear to be related to the amount of root resorption. Future studies with a larger sample size are needed to evaluate the longterm effect of piezocision-assisted orthodontic tooth movement. 


\section{Abbreviations}

CBCT: Cone-beam computed tomography; TO: Initial orthodontic records visit; T1: End of en-masse retraction; HU: Hounsfield Units; ICC: Intra-class correlation coefficient; SPSS: Statistical Package for Social Sciences.

\section{Acknowledgments}

Not applicable.

\section{Author contributions}

$\mathrm{AH}, \mathrm{SA}, \mathrm{RM}$ and NA collecting the sample, performed the treatment for all patients and drafted the manuscript. MH Performed the CBCT measurements and drafting of the manuscript. KZ Drafted the introduction, methods, and discussion and proofread the manuscript. GA Performed statistical analysis for all data and drafting of the manuscript. RA Helped write the manuscript and proofread the manuscript. AH Proposed the idea and wrote the manuscript. All authors read and approved the final manuscript.

\section{Funding}

Not applicable.

\section{Availability of data and materials}

The datasets used and analyzed during the current study are available from the corresponding authors upon reasonable request.

\section{Ethics approval and consent to participate}

This study was approved by the Research Ethics Committee of the Faculty of Dentistry at King Abdulaziz University (No. 078-16) and was registered under the Clinical Trial Registry (NCT03180151). The study was conducted in accordance with the ethical standards of the Declaration of Helsinki and the CONSORT statement of the updated guidelines for reporting randomized clinical trials was followed. All participants gave their informed written consent to participate.

\section{Consent for publication}

Not applicable.

\section{Competing interests}

The authors certify that they have no competing interests.

\section{Author details}

1 Department of Orthodontics, Alnoor Hospital, Ministry of Health, Makkah, Saudi Arabia. ${ }^{2}$ Department of Endodontics, Faculty of Dentistry, King Abdul Aziz University, Jeddah, Saudi Arabia. ${ }^{3}$ Department of Orthodontics, Faculty of Dentistry, King Abdulaziz University, Jeddah, Saudi Arabia. ${ }^{4}$ Faculty of Dentistry, King Abdulaziz University, Jeddah, Saudi Arabia. ${ }^{5}$ Taibah University, Madinah, Saudi Arabia. ${ }^{6}$ Alfarabi Private College, PO Box 80209, Jeddah 21589, Saudi Arabia.

Received: 4 August 2020 Accepted: 22 December 2020

Published online: 13 January 2021

\section{References}

1. Brezniak N, Wasserstein A. Orthodontically induced inflammatory root resorption. Part I: The basic science aspects. Angle Orthod. 2002:72(2):175-9.

2. Brezniak N, Wasserstein A. Orthodontically induced inflammatory root resorption. Part II: The clinical aspects. Angle Orthod. 2002;72(2):180-4.

3. Santamaria M Jr, Milagres D, Iyomasa MM, Stuani MB, Ruellas AC. Initial pulp changes during orthodontic movement: histomorphological evaluation. Braz Dent J. 2007;18(1):34-9.

4. Antoun JS, Mei L, Gibbs K, Farella M. Effect of orthodontic treatment on the periodontal tissues. Periodontol 2000. 2017:74(1):140-57.

5. Guevara MJ, McClugage SG Jr. Effects of intrusive forces upon the microvasculature of the dental pulp. Angle Orthod. 1980:50(2):129-34.

6. Derringer KA, Jaggers DC, Linden RW. Angiogenesis in human dental pulp following orthodontic tooth movement. J Dent Res. 1996;75(10):1761-6.
7. Perinetti G, Varvara G, Festa F, Esposito P. Aspartate aminotransferase activity in pulp of orthodontically treated teeth. Am J Orthod Dentofacial Orthop. 2004:125(1):88-92.

8. Venkatesh S, Ajmera S, Ganeshkar SV. Volumetric pulp changes after orthodontic treatment determined by cone-beam computed tomography. J Endod. 2014;40(11):1758-63.

9. Guler AY, Isik BK, Esen A, Menziletoglu D: Assessment of pulp volume changes after surgically assisted rapid palatal expansion. J Stomatol Oral Maxillofac Surg 2020.

10. Nixon CE, Saviano JA, King GJ, Keeling SD. Histomorphometric study of dental pulp during orthodontic tooth movement. J Endod. 1993;19(1):13-6.

11. Lazzaretti DN, Bortoluzzi GS, Torres Fernandes LF, Rodriguez R, Grehs RA, Martins Hartmann MS. Histologic evaluation of human pulp tissue after orthodontic intrusion. J Endod. 2014;40(10):1537-40.

12. Subay RK, Kaya H, Tarim B, Subay A, Cox CF. Response of human pulpal tissue to orthodontic extrusive applications. J Endod. 2001;27(8):508-11.

13. Anstendig HS, Kronman JH. A histologic study of pulpal reaction to orthodontic tooth movement in dogs. Angle Orthod. 1972;42(1):50-5.

14. Grunheid T, Morbach BA, Zentner A. Pulpal cellular reactions to experimental tooth movement in rats. Oral Surg Oral Med Oral Pathol Oral Radiol Endod. 2007;104(3):434-41.

15. Alamadi E, Alhazmi H, Hansen K, Lundgren T, Naoumova J. A comparative study of cone beam computed tomography and conventional radiography in diagnosing the extent of root resorptions. Prog Orthod. 2017;18(1):37.

16. Samandara A, Papageorgiou SN, Ioannidou-Marathiotou I, Kavvadia-Tsatala S, Papadopoulos MA. Evaluation of orthodontically induced external root resorption following orthodontic treatment using cone beam computed tomography (CBCT): a systematic review and meta-analysis. Eur J Orthod. 2019:41(1):67-79.

17. Deng Y, Sun Y, Xu T. Evaluation of root resorption after comprehensive orthodontic treatment using cone beam computed tomography (CBCT): a meta-analysis. BMC Oral Health. 2018;18(1):116.

18. Dibart S, Sebaoun JD, Surmenian J. Piezocision: a minimally invasive, periodontally accelerated orthodontic tooth movement procedure. Compend Contin Educ Dent. 2009;30(6):342-4.

19. Hatrom AA, Zawawi KH, Al-Ali RM, Sabban HM, Zahid TM, Al-Turki GA Hassan AH: Effect of piezocision corticotomy on en-masse retraction: A randomized controlled trial. Angle Orthod 2020.

20. Erdfelder E, Faul F, Buchner A. GPOWER: a general power analysis program. Behav Res Methods Instrum Comput. 1996:28(1):1-11.

21. Santamaria M Jr, Milagres D, Stuani AS, Stuani MB, Ruellas AC. Initial changes in pulpal microvasculature during orthodontic tooth movement: a stereological study. Eur J Orthod. 2006;28(3):217-20.

22. Akyalcin S, Alexander SP, Silva RM, English JD. Evaluation of three-dimensional root surface changes and resorption following rapid maxillary expansion: a cone beam computed tomography investigation. Orthod Craniofac Res. 2015;18(Suppl 1):117-26.

23. Alfuriji S, Alhazmi N, Alhamlan N, Al-Ehaideb A, Alruwaithi M, Alkatheeri $N_{\text {, }}$ Geevarghese A. The effect of orthodontic therapy on periodontal health: a review of the literature. Int J Dent. 2014;2014:585048.

24. Javed F, Al-Kheraif AA, Romanos EB, Romanos GE. Influence of orthodontic forces on human dental pulp: a systematic review. Arch Oral Biol. 2015:60(2):347-56.

25. Marrelli M, Codispoti B, Shelton RM, Scheven BA, Cooper PR, Tatullo M, Paduano F. Dental pulp stem cell mechanoresponsiveness: effects of mechanical stimuli on dental pulp stem cell behavior. Front Physiol. 2018;9:1685.

26. Ramazanzadeh BA, Sahhafian AA, Mohtasham N, Hassanzadeh N, Jahanbin A, Shakeri MT. Histological changes in human dental pulp following application of intrusive and extrusive orthodontic forces. J Oral Sci. 2009;51(1):109-15.

27. LiY, Deng S, Mei L, Li Z, Zhang X, Yang C, LiY, Prevalence and severity of apical root resorption during orthodontic treatment with clear aligners and fixed appliances: a cone beam computed tomography study. Prog Orthod. 2020;21(1):1.

28. Zawawi KH, Malki GA. Radiographic comparison of apical root resorption after orthodontic treatment between bidimensional and Roth straightwire techniques. J Orthod Sci. 2014;3(4):106-10. 
29. Popp TW, Artun J, Linge L. Pulpal response to orthodontic tooth movement in adolescents: a radiographic study. Am J Orthod Dentofacial Orthop. 1992;101(3):228-33.

30. Tjäderhane L. Dentin basic structure, composition, and function. In: Versiani MA, Basrani B, Sousa-Neto MD, editors. The Root Canal Anatomy in Permanent Dentition. Cham: Springer; 2019. p. 17-27.

31. Frost HM. A 2003 update of bone physiology and Wolff's Law for clinicians. Angle Orthod. 2004;74(1):3-15.

32. Patterson BM, Dalci O, Papadopoulou AK, Madukuri S, Mahon J, Petocz P, Spahr A, Darendeliler MA. Effect of piezocision on root resorption associated with orthodontic force: a microcomputed tomography study. Am J Orthod Dentofacial Orthop. 2017;151(1):53-62.

\section{Publisher's Note}

Springer Nature remains neutral with regard to jurisdictional claims in published maps and institutional affiliations.
Ready to submit your research? Choose BMC and benefit from:

- fast, convenient online submission

- thorough peer review by experienced researchers in your field

- rapid publication on acceptance

- support for research data, including large and complex data types

- gold Open Access which fosters wider collaboration and increased citations

- maximum visibility for your research: over $100 \mathrm{M}$ website views per year

At BMC, research is always in progress.

Learn more biomedcentral.com/submissions 